\title{
Organic synthesis in the Smith Group: a personal selection of a dozen lessons learned at the University of Pennsylvania
}

\author{
Kevin PC Minbiole
}

The passionate study of the complex and ever-evolving discipline of organic synthesis over more than a four-decade span is certain to elucidate meaningful and significant lessons. Over this period, Amos B. Smith III, the Rhodes-Thompson Professor of Chemistry and Member of the Monell Chemical Senses Center at the University of Pennsylvania, has mentored well over 100 doctoral and masters students, more than 200 postdoctoral associates and numerous undergraduates, in addition to collaborating with a wide spectrum of internationally recognized scholars. His research interests, broadly stated, comprise complex molecule synthesis, the development of new, versatile and highly effective synthetic methods, bioorganic and medicinal chemistry, peptide mimicry chemistry and material science. Each area demands a high level of synthetic design and execution. United by a passion to unlock the secrets of organic synthesis, and perhaps of Nature itself, innumerable lessons have been, and continue to be, learned by the members of the Smith Group. This lead article in a Special Issue of the Journal of Antibiotics affords an opportunity to share some of those lessons learned, albeit a small selection of personal favorites.

The Journal of Antibiotics (2016) 69, 192-202; doi:10.1038/ja.2016.21; published online 2 March 2016

\section{THE EARLY YEARS: PHOTOCHEMISTRY CAN SERVE AS AN ANCHOR FOR CONCISE SYNTHESES, INSTALLATION OF FUNCTIONALITY AND THE DISCOVERY OF NEW TRANSFORMATIONS}

The research experience of Smith began in the Laboratory of Professor Harold W. Heine at Bucknell University in Lewisburg, Pennsylvania, Smith's home town; thanks to Heine's "gamble" on a then 18-year-old "townie," his first publication concerning the isomerization of 1,3-diphenyl-2,2-dichloroaziridine was reported in July 1963. ${ }^{1}$ After graduation from Bucknell (B.S./M.S. 4-year combined degree), and a year in Medical School at the University of Pennsylvania, Smith pursued his Ph.D. and a subsequent year of postdoctoral study under the mentorship of Professor William C. Agosta at the Rockefeller University (1967-1972, 1973). During those years, the ability of photochemistry as a tool in organic syntheses to furnish varied and useful molecular architectures was becoming more evident. $^{2}$ As illustrated in Figure 1, exposure of simple starting materials, particularly cyclopentenones and acyl cyclopentenes, to as little as 15 min of irradiation from a mercury arc lamp led to remarkable and often unprecedented transformations. Of significant interest was the strain energy that was often incorporated into the resultant molecules, including cyclopropyl esters and cyclobutanones, which opened the doors to subsequent reactions. This productive time in the Agosta Laboratory (leading to 13 publications!) provided the foundation and momentum that Smith carried into his early research career in the
Department of Chemistry and the Monell Chemical Senses Center at the University of Pennsylvania.

During the early Penn years, the use of photochemistry to access interesting molecular architectures proved a recurring theme: two investigations are highlighted here-quadrone and echinosporin (Figures 2 and 3). The complicated polycyclic structure of quadrone represented an ideal proving ground for the development of new synthetic strategies, with over a dozen syntheses reported from the 1980s onward. Photochemistry set the stage for the Smith synthetic campaign; ${ }^{3}$ an early $[2+2]$ cycloaddition of isobutylene installed a strained cyclobutane functionality that was later rearranged via an acid-promoted Cargill rearrangement ${ }^{4}$ to forge a key multicyclic system (Figure 2). Although this was not the first assembly of quadrone, the Smith approach demonstrated the power of photochemistry to efficiently advance a synthesis, as well as to potentiate the cornerstone rearrangement step.

Subsequent assembly of the antitumor metabolite (-)-echinosporin also entailed a key [2+2] cycloaddition, as illustrated in Figure 3.5 The early cycloaddition of cyclopentenone with a cyclic enol ether proved remarkable on a number of levels; the adduct illustrated was generated as the major product with preference for addition in a head-to-tail fashion, as well as on the exo face of the bicyclic system, to deliver a cis/trans-ring fusion with respect to the cyclobutane. The potential energy of this system was then released in a later Parikh-Doering oxidation, ${ }^{6}$ which set the stage for the final, albeit difficult lactonization, leading to ( - )-echinosporin. 


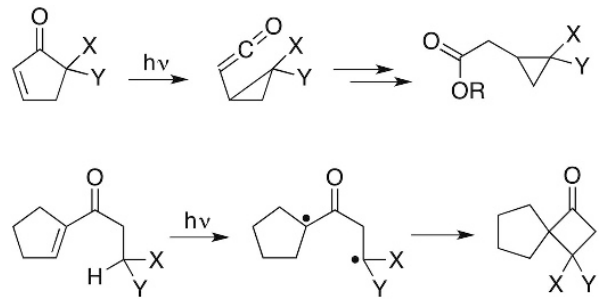

Figure 1 Early Agosta-Smith photochemistry.

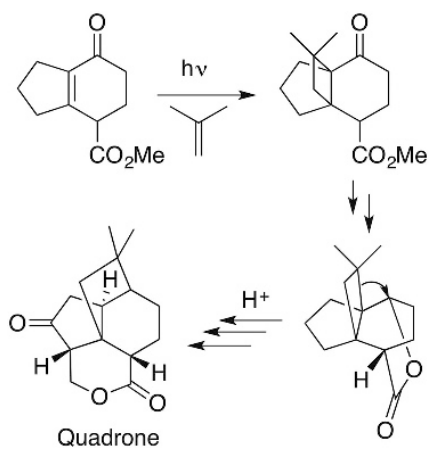

Figure 2 Smith Group assembly of quadrone.

Taken together, these examples serve to illustrate pioneering work in exploiting photochemical transformations in complex natural product total synthesis.

\section{ARCHITECTURALLY COMPLEX INDOLE DITERPENE ALKALOIDS PROVIDE VEXING PROBLEMS LEADING TO GREAT INSIGHTS, NEW METHODS AND LESSONS IN TENACITY}

The indole alkaloids comprise one of the most interesting and challenging classes of natural products. Such compounds represent some of history's most notorious poisons (strychnine and the ergot alkaloids!), and with their molecular architecture represent some of the greatest challenges of natural product total synthesis. ${ }^{7,8}$ The Smith Group entered into a several decade-long relationship with a number of indole diterpene alkaloids, with particular interest in the paspaline class, the most complex examples including penitrem $\mathrm{D}^{9}$ and nodulisporic acid D. ${ }^{10}$ The imposing nonacyclic ring system in penitrem D, featuring an unusual 8-membered ring, as well as the highly substituted cyclobutane ring, intrigued Smith (Figure 4). The symptoms presented by livestock afflicted by poisonings with such indole alkaloids are similar to those associated with Wilson's disease, multiple sclerosis, Parkinson's disease and epilepsy and, as such, are suggestive of a possible common neurochemical mechanism. ${ }^{11}$

The Smith synthetic campaign ${ }^{9}$ was again able to incorporate a photochemical [2+2] cycloaddition tactic, in an efficient approach to the cyclobutane ring. A novel autoxidation to introduce the $\mathrm{C}(22)$ tertiary hydroxyl group, required for tremorgenic activity, was then discovered-merely stirring an enone precursor in the presence of silica gel and air led to the stereoelectronically and sterically favored introduction of a peroxide moiety, which in turn was reduced with triphenylphosphine. Finally, after years (literally) of optimization and production of the requisite starting materials, the western and eastern hemispheres of penitrem D were brought together in a multistage coupling sequence, furnishing key heptacyclic intermediate $\mathbf{C}$ in $81 \%$ yield. Elaboration to the natural product capped a 43-step total synthesis from the (-)-Wieland-Miesher ketone. More recently (2015), still intrigued with such alkaloids, Smith and coworkers

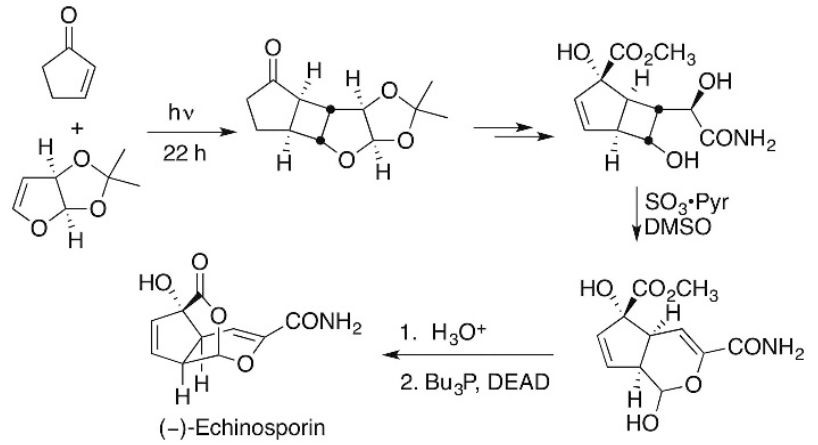

Figure 3 Smith Group assembly of (-)-echinosporin.

recorded the first total synthesis of the similarly challenging alkaloid, nodulisporic acid D, again exploiting the union of two advanced intermediates (Figure 4, inset). ${ }^{10}$

\section{ORGANIC SYNTHESIS IS OFTEN BEST PAIRED WITH OTHER DISCIPLINES: CHEMICAL ECOLOGY CAN SHARE SURPRISING INSIGHTS}

Smith's initial position at Penn involved a joint appointment with the recently established Monell Chemical Senses Center. Around this time, the field of chemical ecology was taking shape, largely following in the pioneering footsteps of Professors Jerry Meinwold and Tom Eisner at Cornell. Smith, having had some experience at Rockefeller with Agosta's interest in a hamster pheromone project, ${ }^{12}$ was eager to enter this field as well; an opportunity presented itself at Monell through two established animal behavioral scientists-Gary Beauchamp and Gisela Epple. Beauchamp was exploring the scent mark of domestic and wild guinea pigs, ${ }^{13}$ whereas Epple, a primate biologist, had gained important insights regarding the role of pheromones in the sexual behavior of the South American brown-mantled tamarin (Saguinus fuscicollis). ${ }^{14}$ The scent mark of this primate was known to convey significant information to other tamarins, namely the sex, social status and identity of the donor; however, the chemicals responsible for this interaction remained undefined. ${ }^{14}$ Smith and colleagues, exploiting gas chromatographic analysis of the scent mark, accomplished the separation of 17 volatile components-16 saturated and unsaturated butyrate esters, as well as squalene; after initial identification by MS, NMR and microozonolysis (in $\mathrm{CS}_{2}$ at $-65^{\circ} \mathrm{C}$ !), the structures were confirmed by chemical synthesis (Figure 5, left). ${ }^{15}$ Smith and Epple, in collaboration with Professor Peter Jurs at Pennsylvania State University, were then able to apply statistical tools to recognize patterns that would permit accurate correlation of the scent's chemical fingerprint to the donor's gender and subspecies. ${ }^{16}$ In the end, a determined effort had led to the replication of the "instant" analysis already occurring in Nature by the tamarins.

Work at the Monell Center has continued in the years since, and has led to a particularly noteworthy insight-the synthesis and structure confirmation, ${ }^{17,18}$ including absolute stereochemistry, of a key component of extra-virgin olive oil, (-)-oleocanthal, first recognized as important by Beauchamp and coworkers. ${ }^{17,19}$ Countries with high use of the "Mediterranean diet," which prominently features olive oil, are known to have less heart disease and Alzheimer's disease. $^{20}$ Interestingly, (-)-oleocanthal possesses activity nearly identical to that of ibuprofen, a nonsteroidal anti-inflammatory/ analgesic agent (Figure 5, right). ${ }^{16}$ The selective inhibition of COX enzymes by either of the enantiomers of this compound has received considerable interest. $^{21}$ 
<smiles>C=CC(=O)OCc1ccccc1</smiles>

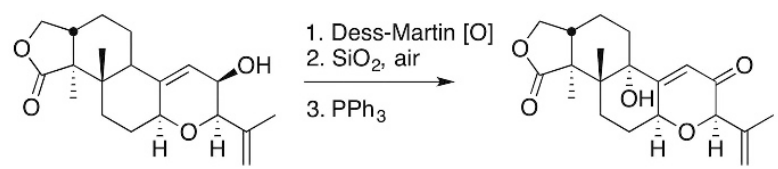

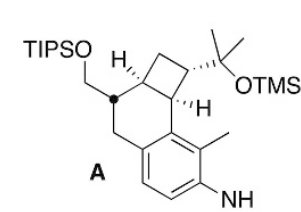

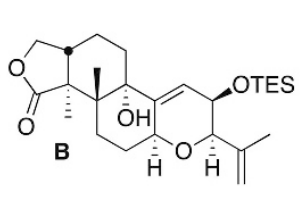
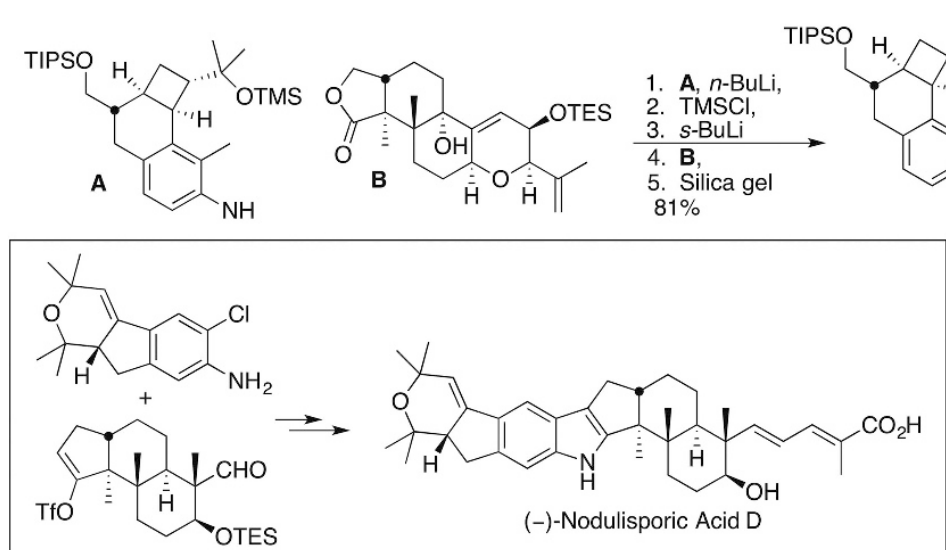

C

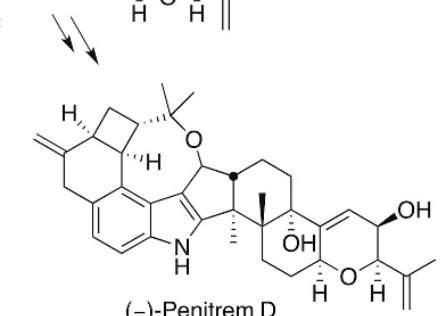

Figure 4 Highlights of the Smith Group total syntheses of (-)-penitrem D and of ( - )-nodulisporic acid D.

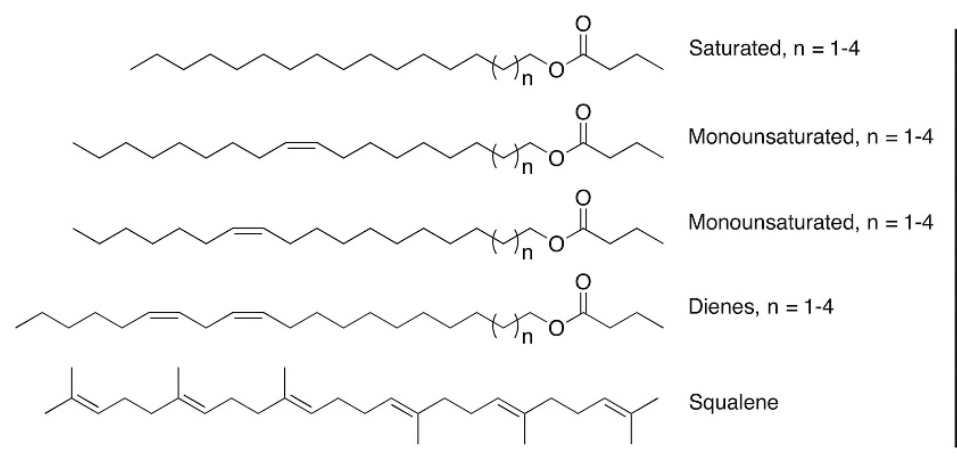

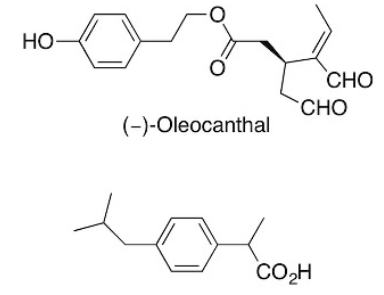

Ibuprofen

Figure 5 Scent mark constituents of the Brown-Mantled Tamarin (left); (-)-oleocanthal, isolated from extra-virgin olive oil, and ibuprofen (right).

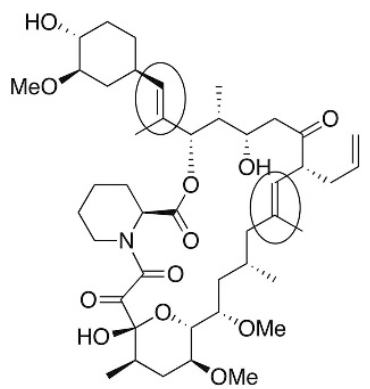

$(-)-F K 506$

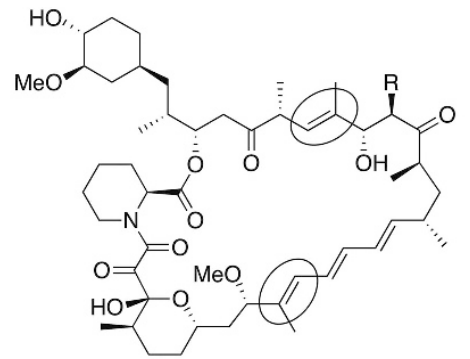

$(-)$-Rapamycin $(\mathrm{R}=\mathrm{OMe})$ (-)-Demethoxyrapamycin $(\mathrm{R}=\mathrm{H})$

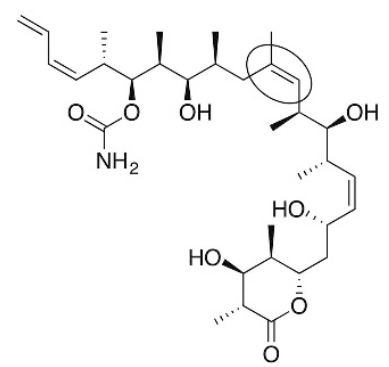

(+)-Discodermolide

Figure 6 The structures of (-)-FK506, (-)-rapamycin and its demethoxy congener, as well as (+)-discodermolide. Key trisubstituted alkenes are highlighted.

\section{"HOT TARGETS": IMMUNOSUPPRESSANTS CAN PROPEL EXCITEMENT AS WELL AS LEARNING}

As a research group heavily involved in the total synthesis of architecturally complex bioactive natural products, it was inevitable that at many points over the past four decades, the Smith Research Group has and continues to undertake synthetic campaigns towards "hot target" compounds at the same time as other research groups. One class of molecules that received significant simultaneous attention from the synthetic community was a class of immunosuppressants, namely ( - )-FK506, ( - )-rapamycin and its demethoxy congener, as well as (+)-discodermolide and analogs thereof (Figure 6). ${ }^{22}$ Given the medical importance of the potent immunosuppressant cyclosporine, construction of natural product targets with related biological activity pushed to the forefront of organic synthesis in the early 1990s. Elegant syntheses of these targets were emerging from the groups of Danishefsky, ${ }^{23,24}$ Nicolaou, ${ }^{25}$ Schreiber ${ }^{26,27}$ and Sih, ${ }^{28}$ among many 
others; $;^{29,30}$ the development of new synthetic organic methods also proved essential.

The Smith Group focused on major methodological advances in this realm ${ }^{31}$ including dithiane couplings (which continues to remain a central focus in the Smith Group; vide infra) and the stereocontrolled assembly of the trisubstituted alkenes that appear in each of these immunosuppressants. As illustrated in Figure 7a, Smith and colleagues demonstrated a zirconocene-assisted vinyl alane construction, ${ }^{32}$ which after conversion to the ate complex (BuLi) and then reaction with an epoxide, led to the requisite trisubstituted olefin on up to decagram scale. $^{33,34}$ Figure $7 \mathrm{~b}$ next illustrates Smith's use of the copper-mediated alkylation of vinyl triflates in complex acyclic systems, ${ }^{33,35}$ whereas Figure $7 \mathrm{c}$ records both the chemoselective and stereoselective functionalization of a diyne, installing a vinylstannane/alkyne in high yield and with either $E$ or $Z$ selectivity. ${ }^{36}$

\section{C60: A SYSTEM ENTIRELY COMPOSED OF CARBON ATOMS HOLDS GREAT INTEREST, VERSATILITY AND MANY PECULIARITIES}

In addition to collaborations with the Monell Chemical Senses Center, the early years in the Smith Group led to the partnerships with Professor Paul Heiney in the Physics Department at Penn and colleagues in the Laboratory for Research on the Structure of Matter (LRSM) at Penn. At the outset, this collaboration led to the synthesis and physical characterization (utilizing low angle X-ray scattering) of several known discotic liquid crystals of interest to the Lehn Group in Paris. ${ }^{37}$

Later in the mid-to-late 1980s, materials science underwent a major paradigm shift, as the elusive and wondrous C60 or commonly called Buckminster Fullerene broadened the definition of the allotropes of carbon. A particularly exciting event was reported in 1990: C60 was rendered readily available and in useful amounts by the Kratschmer-Huffman electric arc method. ${ }^{38}$ Smith and collaborators at the LRSM seized upon the ready availability of C60 and were able to perform some of the first derivatizations of the fullerenes; importantly the full structural characterizations of the resulting epoxides and cyclopropanes of C60 and C70 were accomplished for the first

a

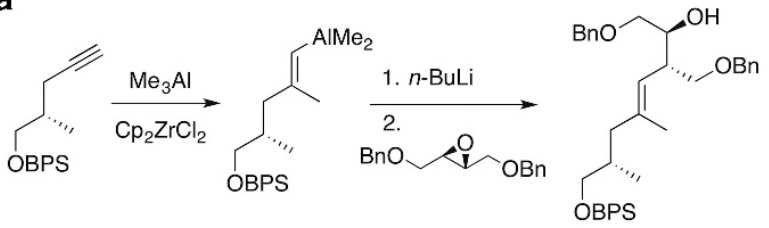

b
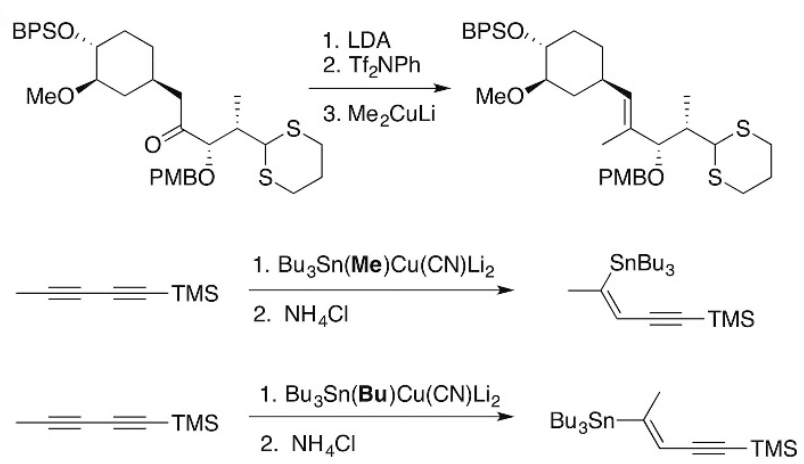

Figure 7 Stereoselective constructions of trisubstituted alkenes in Smith's syntheses of immunosuppressive agents, using (a) vinyl alane, (b) vinyl triflate, and (c) vinyl stannane intermediates. time. ${ }^{39,40}$ In addition, structural characterization studies with highly purified samples (99.5\%) of C60 and C70 were explored in collaboration with LRSM colleagues employing synchrotron irradiation over a temperature range of $11-300 \mathrm{~K}$, demonstrating that C60 indeed assumes a more ordered orientation (i.e., a phase transition) when cooled to low temperatures. ${ }^{41}$ Finally, a collaboration with Martin Saunders at Yale University demonstrated the utility of incarcerated helium atoms (i.e., 1-2\%) inside the C60 and C70 molecules (Figure 8), made available by carrying out the KratschmerHuffman arc synthesis in the presence of ${ }^{3} \mathrm{He} .{ }^{42}$ Such ${ }^{3} \mathrm{He}$ incarcerated systems permitted facile identification of the number of reaction products that result in fullerene derivatization reactions, given that ${ }^{3} \mathrm{He}$ serves as a highly diagnostic NMR probe; specifically, each different fullerene ${ }^{3} \mathrm{He}$ structure displays a unique singlet in the ${ }^{3} \mathrm{He}$ NMR spectrum. ${ }^{42}$

\section{COLLABORATIONS WITH COLLEAGUES LEAD TO THE DESIGN OF ELEGANT SYSTEMS TO MIMIC SOME OF NATURE'S MOST POTENT ARCHITECTURES}

Of all the collaborations the Smith Group has enjoyed, there has been none greater than the one that began in 1987, when Ralph Hirschmann retired from his position as the Senior Vice President, Chemistry at Merck Research Laboratories. Hirschmann, at age 65, was certainly not in the mood for retirement, and so proposed joining the Chemistry Department at Penn as a Research Professor, with the specific idea to collaborate with K. C. Nicolaou (then a faculty member at Penn) and Smith on problems of mutual interest. Two significant highlights of this collaboration were the development of novel peptide $\beta$-strand $/ \beta$-sheet mimics, ${ }^{43}$ utilizing a pyrrolinone scaffold by the Smith Group, and monosaccharide-based mimics of the peptide $\beta$-turn, ${ }^{44}$ developed by the Nicolaou Group, both shown in Figure 9.

The pyrrolinone project ultimately led to a viable synthetic route to the synthesis of peptide analogs, later termed foldamers by Gellman, ${ }^{45}$ addressing a longstanding pharmacokinetics problem in medicinal chemistry: peptides are intriguing medicinal targets but have poor stability. Two parallel programs were initiated to exploit the polypyrrolinones, one directed at the design of peptidomimetic
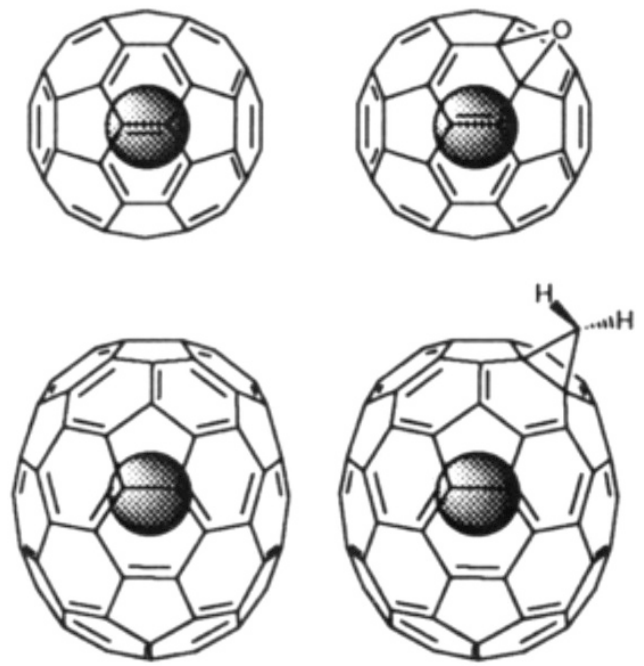

Figure 8 Helium-incarcerated fullerene derivatives prepared in the Smith Laboratory. Reprinted (adapted) with permission from Smith et al. ${ }^{42}$ Copyright 1994 American Chemical Society. 


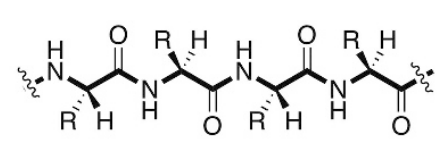

Peptide $\beta$-Strand Conformation

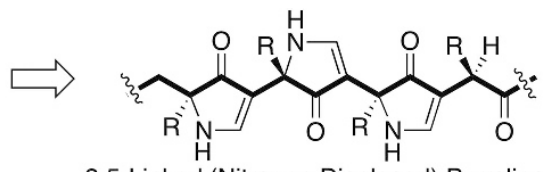

3,5-Linked (Nitrogen Displaced) Pyrrolinones

$\beta$-Strand / $\beta$-Sheet Mimetics

Turned Mimetics, Helical Mimetics

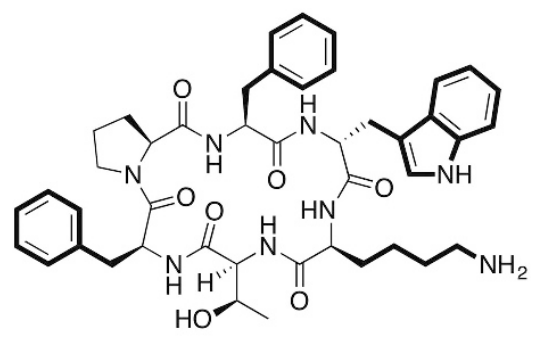

L-363,301, a $\beta$-Turn

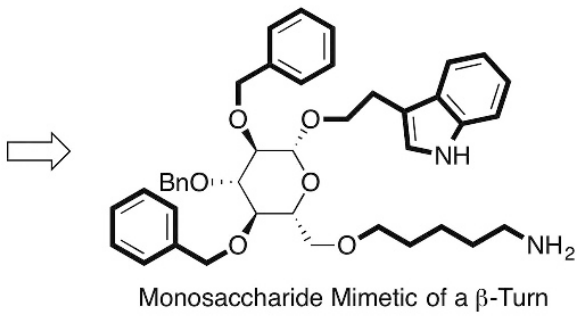

Figure 9 Synthetic mimics of peptide $\beta$-strands and cyclic peptide $\beta$-turns developed through the Hirschmann-Nicoloau-Smith collaboration.
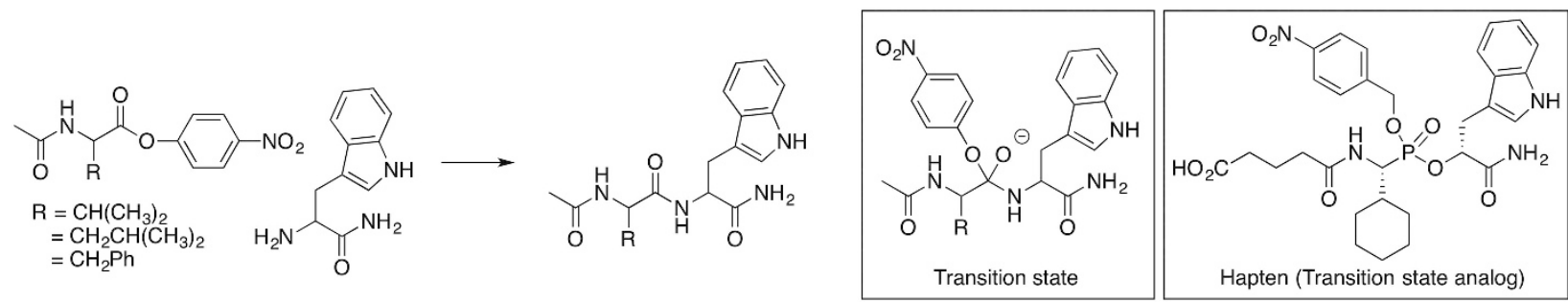

Figure 10 The coupling of a p-nitrophenyl ester and tryptophan amide, along with the transition state and hapten used to generate catalytic antibodies.

receptor agonists/antagonists, ${ }^{46}$ and the second focused on the development of protease inhibitors. ${ }^{47}$ For the peptide $\beta$-turn mimetic project, Nicolaou and coworkers chose D-glucose as a core structure, in light of its low cost, facile synthetic elaboration and three-dimensional trajectories of functional groups; analogs of somatostatin (and its truncated agonist peptide L-363,301) represented a key target. ${ }^{44}$ High levels of receptor affinity of selected analogs, along with the discovery that such peptidomimetics proved active against several chemically distinct receptors, led to the hypothesis that such modified monosaccharides could access multiple potential binding modes. ${ }^{44}$ It is with great fondness that the contributions of Ralph Hirschmann are remembered; he spent nearly two decades as a cherished collaborator and co-mentor of the Smith Group.

\section{ANTIBODIES HAVE REMARKABLE POWER TO RECOGNIZE AND THEREBY FACILITATE AMAZING OUTCOMES}

The laboratory synthesis of peptides has rightfully earned a privileged position in organic chemistry. The Nobel Prize-winning work of Bruce Merrifield (interestingly the Chair of Smith's Ph.D. Thesis Committee at Rockefeller) brought in the 1960s solid-phase techniques to greatly simplify this enormously challenging task, ${ }^{48}$ and when coupled with HPLC purification techniques, ${ }^{49}$ led to what are now workhorse strategies for peptide assembly. Still of great concern to the synthetic community in the 1990s was the ability to forge individual peptide bonds at will, particularly for large fragment unions. Challenges in this arena, particularly when facing solubility issues of protected-peptide fragments, led to the developments of new reagents and strategies, including the utilization of enzymes to forge bonds. ${ }^{50}$ The demonstration by Lerner, Schultz and Benkovic in the late 1980s of the use of antibodies as catalysts for organic transformations suggested that antibodies too could extend the toolkit of strategies for the construction of peptide bonds. ${ }^{51}$

To this end, the Hirschmann and Smith Group developed a collaboration with Benkovic, at Pennsylvania State University, to extend this concept to peptide synthesis. ${ }^{52,53}$ The synthesis of an appropriate hapten (an elicitor of an immune response) was, of course, a prerequisite; a multidisciplinary approach in the Smith/ Hirschmann/Benkovic Groups led to the design and synthesis of a phosphonate diester hapten, as illustrated in Figure 10, to mimic the transition state of peptide bond formation. A cyclohexyl group was installed in the hapten to permit for greater variability of hydrophobic amino acid side chains; the p-nitrophenyl was crucial to favor substrate binding, as it is not present in the coupled product. Monoclonal antibodies were then induced by this hapten at Penn State. Importantly, the derived antibodies were shown to catalyze the coupling of $p$-nitrophenyl esters of $\mathrm{N}$-acetyl valine, leucine and phenylalanine with tryptophan amide to form dipeptides, in yields of $44-94 \%$ ! With multiple turnovers achieved, rates over $1000 \times$ that of background reaction, and no catalytic hydrolysis, a novel strategy for the preparation of peptide bonds was demonstrated.

\section{FLEXIBLE REARRANGEMENTS CAN UNITE COMPLEX FRAGMENTS AND PROPEL THEM TOWARDS AN EFFICIENT TOTAL SYNTHESIS}

The complex synthetic endeavors undertaken by the Smith Group have served as an ardent proving ground for many new synthetic 
strategies and tactics. Naturally, the Smith Group routinely takes stock of the current synthetic literature, and seeks to apply some of the most interesting and useful reactions in their synthetic ventures. It did not escape their notice when Nicos Petasis, a previous Penn Ph.D. student of Nicolaou, and now a professor at the University of Southern California, reported a useful tetrahydropyran assembly tactic, ${ }^{54}$ based on a Ferrier type II reaction. Although this reaction has been reviewed more fully elsewhere in this Special Issue of the Journal of Antibiotics, ${ }^{55}$ the importance of the Petasis-Ferrier rearrangement to the Smith Group deserves mention.

Smith and coworkers have incorporated the Petasis-Ferrier reaction into eight of their natural product synthetic ventures; together these highlight the development of this process as a general union/rearrangement strategy. Indeed, from their first application of the Petasis-Ferrier reaction in the total synthesis of $(+)$-phorboxazole $\mathrm{A}^{56}$ Smith and coworkers recognized that this reaction was ideal for convergent and complex synthesis. Two potentially large fragments as recently demonstrated with (-)-enigmazole A (2015) can be connected, and then rearranged to form the requisite 2,6-cis-disubstituted tetrahydropyran, with the inherent symmetry in this rearrangement permitting for two different modes of disconnection from the retrosynthetic sense, as seen in Figure 11 . The flexibility and efficiency of this rearrangement thus made it instrumental for the construction of $(+)$-zampanolide, ${ }^{57}(+)$-dactylolide, ${ }^{57}(+)$-spongistatin $1,{ }^{58}(-)$-kendomycin, ${ }^{59} \quad(-)$-clavosolide $\mathrm{A},{ }^{60}$ and $(-)$ okilactomycin, ${ }^{61}(+)$-phorboxazole $\mathrm{A},{ }^{56}$ and, most recently, (-)-enigmazole A (2015); these structures are illustrated at the end of this review.

\section{ANION RELAY CHEMISTRY (ARC): THE RELAY OF NEGATIVE CHARGE ACROSS SPACE CAN LEAD TO THE RAPID CONSTRUCTION OF STRUCTURAL COMPLEXITY IN A SINGLE ROUND-BOTTOM FLASK.}

Dieter Seebach, in his landmark 1979 treatise, ${ }^{62}$ articulated the concept of "umpolung," first introduced by Wittig, ${ }^{63,64}$ indicating how the "reversal" of electron density can lead to clever and unheralded reaction pathways. As did many other groups, the Smith Group found that the use of the versatile Corey-Seebach dithiane anion, ${ }^{65}$ as an acyl anion synthon, provided a particularly attractive tactic in natural product total synthesis. The test of time, however, would reveal that this synthon held much greater levels of utility, as the negative charge generated at the dithiane center can be readily transferred, perhaps multiple times, leading to the forging of multiple bonds in a single reaction. Thus, the Smith Group's formulation and augmentation

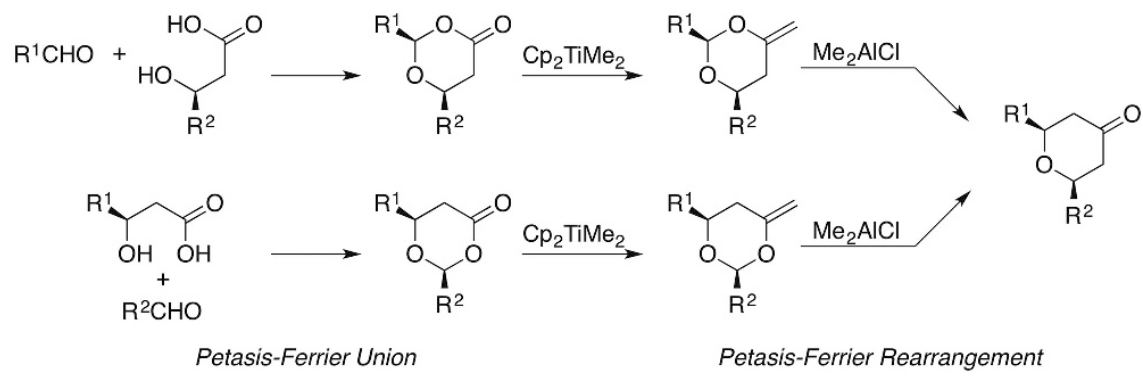

Figure 11 The Petasis-Ferrier union-rearrangement tactic, with illustration of pseudosymmetry elements.

a Anion Relay Chemistry: Type I

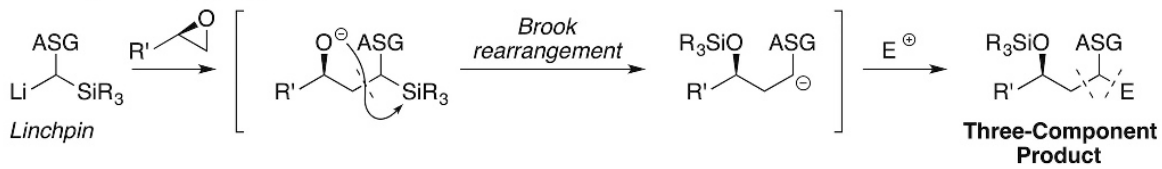

b Anion Relay Chemistry: Type II

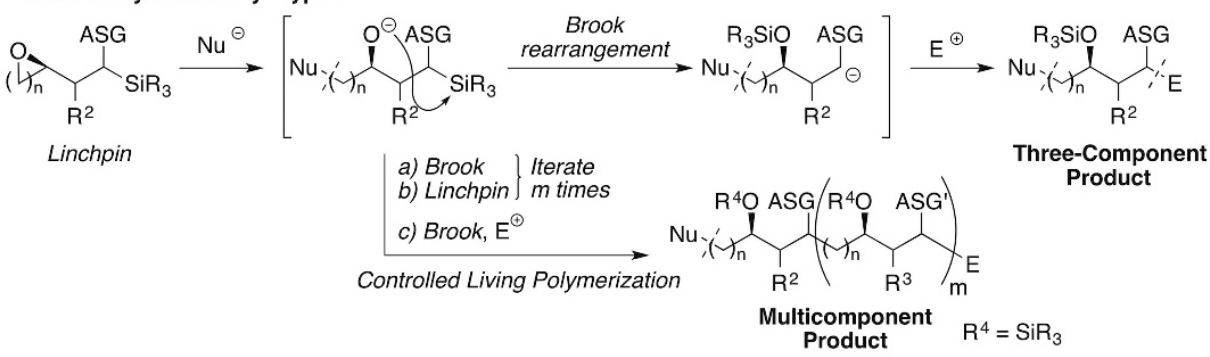

C Anion Relay Chemistry: Through-Bond/Through Space

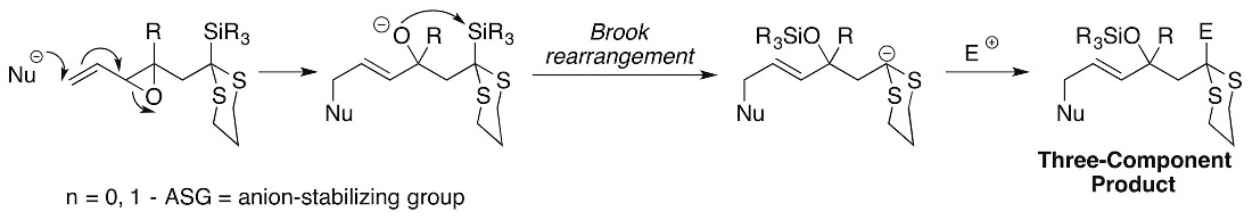

Figure 12 Examples of the (a) type I, (b) type II, and (c) through-bond/through space anion relay strategies. 
of anion relay chemistry (ARC)—a multi-component coupling protocol-ultimately provided a powerful and versatile synthetic tactic, enabling efficient and rapid elaboration of structurally complex scaffolds in a single operation. ${ }^{66}$ Excellent stereochemical control led to the application of this tactic in a number of complex molecule syntheses. General strategies to exploit polyfunctional linchpins (not limited to dithianes!) are illustrated in Figure 12. The type I ARC strategy, initially pioneered by Matsuda in $1979^{67}$ exploiting trimethylsilyl-acetonitrile, and later extended to dithianes by Tietze ${ }^{68}$ and Schaumann, ${ }^{69}$ permits bis-alkylation events to occur at the same carbon atom in a single flask! By controlling the onset of the Brook rearrangement with solvent polarity, temperature or change in gegenion, the Smith Group has been able to introduce two different substituents at the dithiane carbon. This tactic was employed extensively over the years to unite complex fragments in many of the Smith Group complex molecule syntheses. An alternative and potentially much more valuable tactic, type II ARC, was introduced by the Smith Group in $2004 ;{ }^{70}$ this tactic utilizes a single bifunctional linchpin as both an electrophile and latent nucleophile, and as such holds the promise of iteration of charge relay, not unlike "living polymerization" in the construction of block polymers. More recently the Smith Group demonstrated the additional possibility of combining negative charge migration to include through bond and through space as illustrated in Figure $12 \mathrm{c}$ by exploiting an $\mathrm{S}_{\mathrm{N}}{ }^{\prime}$ electrophilic center. ${ }^{71}$

\section{ANION RELAY CONTINUED: THE CHEMISTRY OF ARC LINCHPINS CAN EXTEND BEYOND OUR STANDARD VISION OF COUPLING REACTIONS}

Smith's investigations into charge transfer linchpins in 2012 took an interesting turn with the report of the unification of the ARC tactics with the Denmark/Hiyama palladium-mediated cross-coupling process. ${ }^{72}$ Here, Smith reported the development of a siloxane transfer agent (Figure 13) that could serve initially as an electrophile for an organolithium species, and then as a transfer agent under palladium and $\mathrm{CuI}$ catalysis to achieve cross-coupling reactions that did not require either the stoichiometric formation of an organometallic species or importantly a stoichiometric waste product (e.g., $\mathrm{ZnCl}_{2}$ as in Negishi cross-coupling reactions) beyond Lil. This strategy also avoids the problem of lithium-halogen exchange or homocoupling endemic to most organolithium-based couplings. Vinyl and aryl substrates were equally successful, and importantly the yields were good to excellent (e.g., Figure 13, bottom), including gram-scale reactions. As a further development, a polymer-bound analog of the siloxane transfer agent was designed, synthesized and validated for cross-coupling reactions, permitting ready recycling of this most

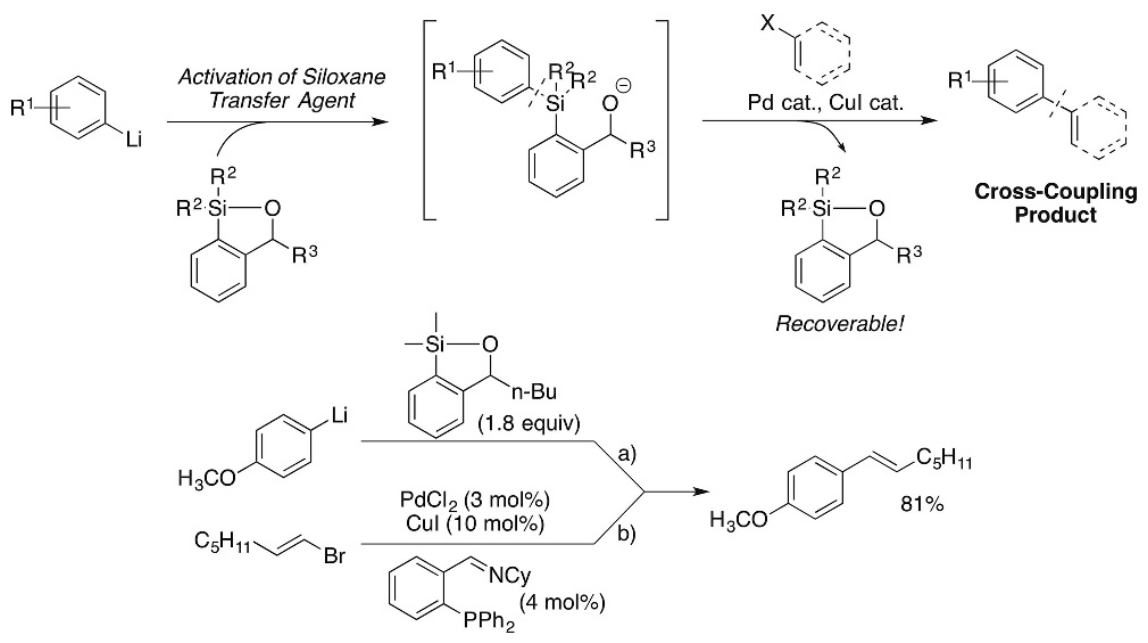

Figure 13 Application of ARC linchpin chemistry to a modified Denmark-Hiyama cross-coupling.

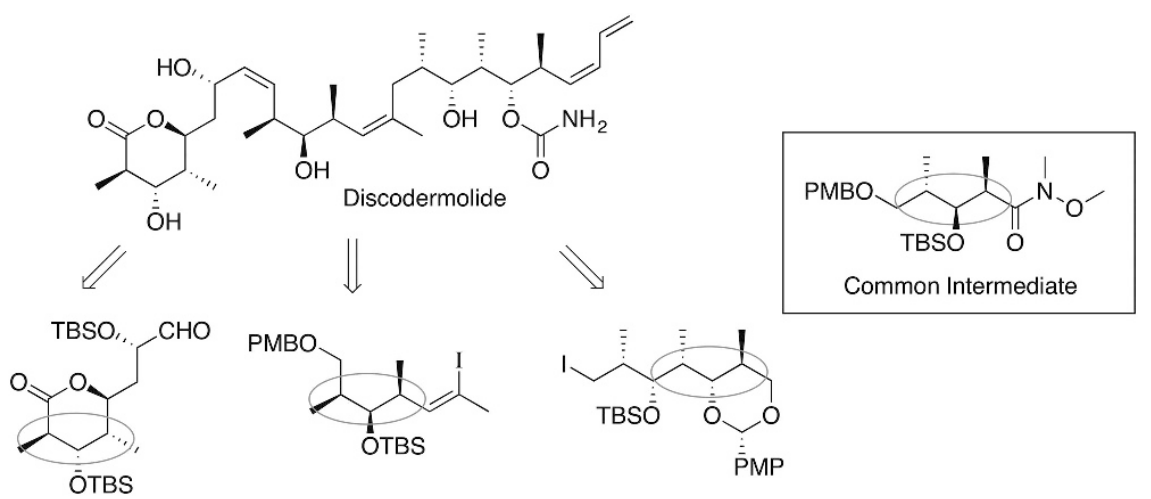

Figure 14 Retrosynthetic analysis for discodermolide, highlighting a repeating stereochemical triad and common synthetic intermediate. A full color version of this figure is available at The Journal of Antibiotics journal online. 
Some of the Target Molecules Synthesised by Professor Amos B Smith III (1981-2015)
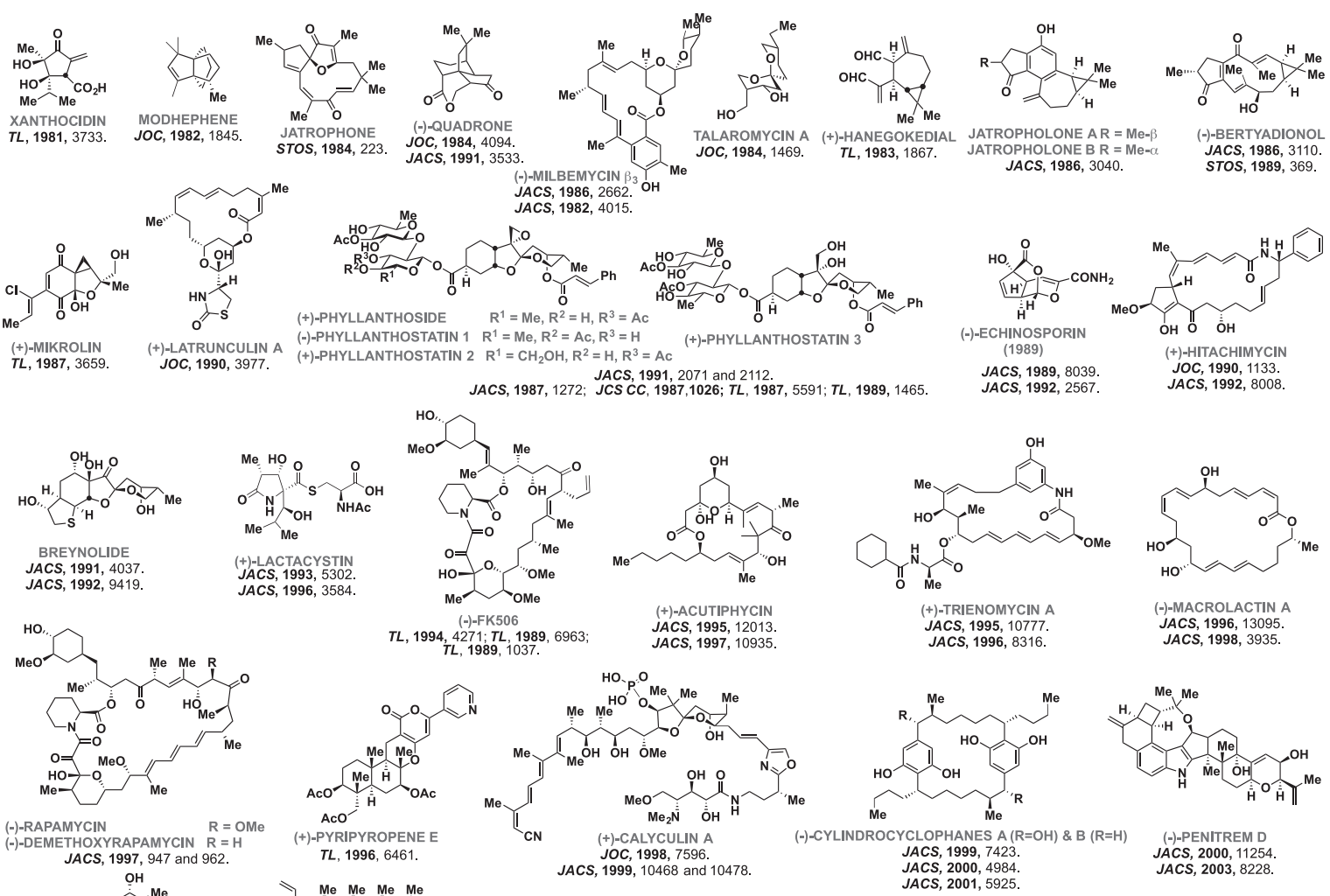

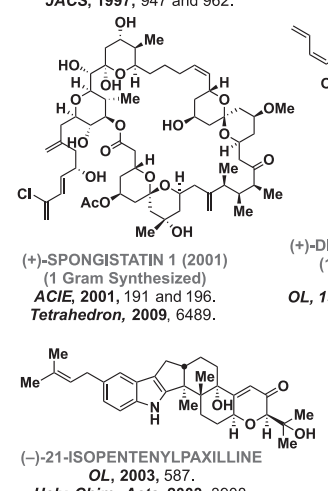

Helv. Chim. Acta, 2003, 3908.

Me me Me me 然 ${ }^{\circ} \mathrm{Me}^{-2}$ mo (+)-DISCODERMOLIDE (1999) (1 Gram Synthesized)
JACS, 2000, 8654. 1999, 1823; OL, 2003, 4405

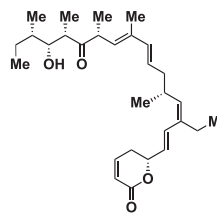

(-)-CALLYSTATIN A

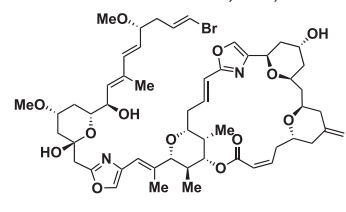

(+)-PHORBOXAZOLE A JACS, 2001, 4834 OL, 2005, 4399 . OLC, 2005, 4399.

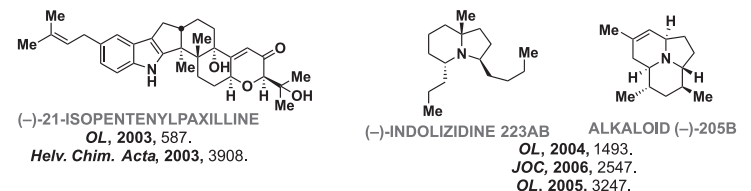

(Me)

O
(-)-KENDOMYCIN JACS, 2005, 6948.

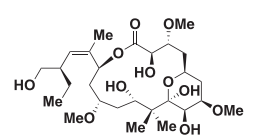

(-)-2-epi-PELORUSIDE A

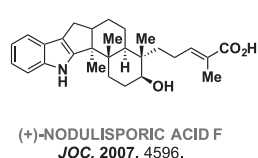

JOC, 2007, 4596 .

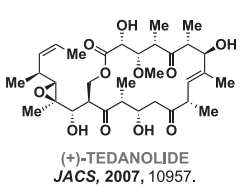

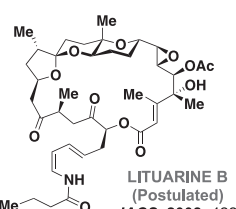

Me NH $\begin{gathered}\text { LITUARINE B } \\ \text { (Postulated) } \\ \text { JACS, 2008, 422 }\end{gathered}$

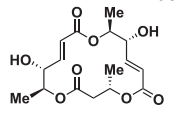

(+)-MACROSPHELIDE A JACS, 1997, 10247.
Tetrahedron, 2005, 3789.

$$
\text { Me OMeO OMe }
$$

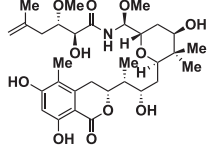
(+)-IRCINIASTATIN A JACS, 2007, 14872.
JACS, 2009, 2348.

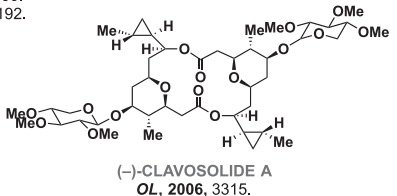
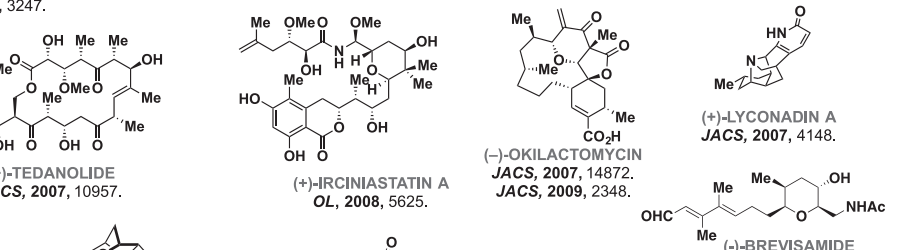

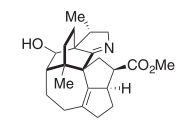

(-)-CALYCIPHYLLINE N JACS, 2014, 870

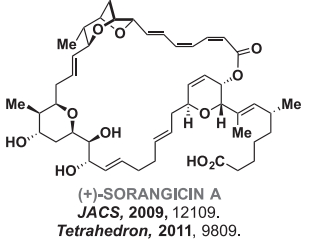

JACS, 2009, 12109.
Tetrahedron, 2011, 9809.

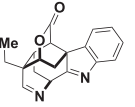

(+)-SCHOLARISINE A JACS, 2012, 4037. JACS, 2013, 51 $\overbrace{}^{M e}$

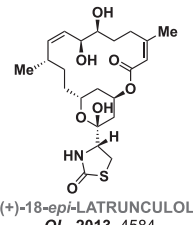

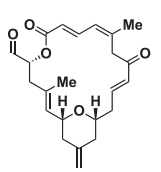

(+)-DACTYLOLIDE OL, 2002, 635.
JACS, 2002, 11102. 
capable transfer agent. ${ }^{73}$ In light of these advantages, this strategy now holds the promise to join the standard "organic chemist's toolbox" of palladium-mediated coupling tactics.

\section{SYNTHESES IN AN ACADEMIC LAB CAN PROVIDE USEFUL QUANTITIES OF COMPLEX AND IMPORTANT MOLECULES}

Total syntheses of natural products have been traditionally motivated by a number of factors. Historically, the positive structural identification of an unknown structure, the opportunity to prepare analogs of natural products, and a strenuous venue for the development of novel synthetic strategies have been the driving force for many synthetic campaigns. A fourth motivation has been the preparation of scarce materials, as oftentimes the natural product isolation process only provides scant amounts of the compound, insufficient for use in clinical settings or even for proper biological assessment. The Smith Group has taken pains to construct significant amounts of several rare-natural product structures with important biological activity; the first undertaking in this arena was the 1-g synthesis of discodermolide in $2000 .^{74}$ The Smith approach updated an earlier synthesis first reported in $1995,{ }^{75}$ wherein a common intermediate, as shown in Figure 14, was prepared and incorporated into three separate synthetic subtargets. Note the "stereochemical triad" present in all of these synthetic targets, which is present in the common intermediate. From the strategic perspective, the terminal oxidation state of each is easily manipulated to permit incorporation in either orientation. This tactic was ultimately merged with synthetic strategies developed by the Ian Paterson Group, as well as at Novartis, ultimately leading to the laboratory synthesis of $60 \mathrm{~g}$ of discodermolide. ${ }^{76}$ In light of the subsequent gram-scale synthesis of $(+)$-spongistatin $1^{77}$ and preparatory-scale preparation of phorboxazole analogs, ${ }^{78}$ a clear demonstration of the scalability of a well-designed academic organic synthesis has doubtlessly been established.

Smith's interest in discodermolide and analogs continues today in collaboration with Drs. Susan Horwitz and Hayley McDaid at the Albert Einstein College of Medicine, where it has been discovered that several discodermolide analogs limit the development of senescence and thereby increase cancer cell death. The inhibition of senescence is thus a potentially new paradigm for cancer chemotherapy. ${ }^{79,80}$

\section{TOTAL SYNTHESIS: A STUDY OF NATURE VIA MIMICRY THAT SERVES AS A PROVING GROUND FOR UTILITY, TENACITY AND RESILIENCE}

The lessons presented herein have each been unique, each providing excitement and perhaps unexpected interesting twists and turns in what must be a most satisfying and continuing career. Importantly, a unifying theme that has surely emerged and continues to evolve from the Smith Laboratory is the joy of a completed total synthesis. A quick look through the history of the Smith Group reveals over 100 papers with "Total Synthesis of..." in the title. Every synthesis in the group started with "getting acquainted" with a molecule, be it from an interesting high-profile article, a seminar, or even a scan through Natural Product Reports. An interesting question is what makes a product of Nature so compelling that a group such as the Smith Group would or should spend years (and at times many years!) in a campaign to achieve what Nature does, with seemingly little effort. The answer is clearly the beautiful molecular architecture! Like any marathon, any and everyone who embarks on a total synthesis is bound to learn a great deal both about the target molecule and themselves along the way. No proving ground is more rigorous for a new reaction than a total synthesis; first and foremost the target structure is non-negotiable, and efficiency is critical. One must also recognize that despite the dozens of successes highlighted in Figure 15, in most cases the targets were not arrived at in precisely the manner initially envisioned. Lessons were thus learned! Indeed, as Woodward taught: employ careful planning, but with the ability to make flexible adjustments ${ }^{81}$ and in doing so, have a deep sense of resilience that will lead to the final achievement; the joy of a total synthesis.

Postscript. Teaching and Learning are Inexorably Entwined Both in the Past and the Future

The formal training of Amos Smith took place in the Laboratories of two extraordinary professors, Harold Heine and William Agosta, without whom the momentum and passion for organic chemistry would have been diminished. These early environments have been transitioned into the mentoring of hundreds of coworkers, many dozen of whom have gone on to become professors (some of whom have sent their students back to Penn!). Years of working "in the trenches" have in general led to one lesson that is perhaps the greatest of all-the best way to gain knowledge about a subject as challenging and wondrous as organic synthesis is to find passionate colleagues and learn together. Inspired and challenged by Nature, one can be assured that the "art and science" of organic synthesis continues in the Smith Group with new ventures in Alzheimer's disease therapy, ${ }^{82} \mathrm{HIV}-1$ entry inhibitors, ${ }^{83-87}$ and peptide stapling/unstapling; ${ }^{88}$ each being advanced by shared enthusiasm, hard work and synthesis.

\section{CONFLICT OF INTEREST}

The author declares no conflict of interest.

\section{ACKNOWLEDGEMENTS}

First and foremost, the author wishes to most sincerely thank to Amos Smith for his tireless devotion to and ferocious support of his students, postdoctoral fellows and collaborators, to say nothing of his Penn faculty colleagues, as well as to this author regarding this manuscript. The hundreds of members and graduates of the Smith Group are acknowledged for their significant laboratory efforts to propel these developments forward. Prof. Karl Hale is specifically acknowledged for assistance with preparation of the figures.

1 Heine, H. W. \& Smith, A. B. III Isomerization of 1,3-diphenyl-2,2-dichloroaziridine. Angew. Chem. 75, 669-670 (1963).

2 Agosta, W. C., Smith, A. B. III, Kende, A. S., Eilerman, R. G. \& Benham, J. The intramolecular photorearrangement of cyclopentenones. Tetrahedron Lett. 10, 4517-4520 (1969).

3 Smith, A. B. III \& Konopelski, J. P. Total synthesis of (+)-quadrone: assignment of absolute stereochemistry. J. Org. Chem. 49, 4094-4095 (1984).

4 Cargill, R. L., Jackson, T. E., Peet, N. P. \& Pond, D. M. Acid-catalyzed rearrangements of $\beta$ - $\gamma$-unsaturated ketones. Acc. Chem. Res. 7, 106-113 (1974).

5 Smith, A. B. III, Sulikowski, G. A., Sulikowski, M. M. \& Fujimoto, K. Applications of an asymmetric [2+2]-photocycloaddition. Total synthesis of (-)-echinosporin. Construction of an advanced 11 deoxyprostaglandin intermediate. J. Am. Chem. Soc. 114, 2567-2576 (1992)

6 Parikh, J. R. \& Doering, W. V. E. Sulfur trioxide in the oxidation of alcohols by dimethyl sulfoxide. J. Am. Chem. Soc. 89, 5505-5507 (1967).

7 Woodward, R. B. \& Doering, W. E. The total synthesis of quinine. J. Am. Chem. Soc. 67, 860-874 (1945).

8 Stork, G. et al. The first stereoselective total synthesis of quinine. J. Am. Chem. Soc. 123, 3239-3242 (2001).

9 Smith, A. B. III et al. Tremorgenic Indole alkaloids. The total synthesis of (-) penitrem D. J. Am. Chem. Soc. 125, 8228-8237 (2003).

10 Zou, Y., Melvin, J. E., Gonzales, S. S., Spafford, M. J. \& Smith, A. B. III. Total synthesis of (-)-nodulisporic acid D. J. Am. Chem. Soc. 137, 7095-7098 (2015).

11 Kochanowska-Karamyan, A. J. \& Hamann, M. T. Marine indole alkaloids: potential new drug leads for the control of depression and anxiety. Chem. Rev. 110, 4489-4497 (2010).

12 Singer, A. G., Macrides, F. \& Agosta, W. C. in Chemical Signals in Vertebrates and Aquatic Invertebrates (eds Müller-Schwarze, D. \& Silverstein, R. M) 365-375 (Plenum Press, New York, NY, 1980). 
13 Beauchamp, G. K. Diet influences attractiveness of urine in guinea pigs. Nature 263, 587-588 (1976).

14 Epple, G. The behavior of marmoset monkeys (Callithricidae). Primate behavior developments in field and laboratory research 4, 195-239 (1975).

15 Smith, A. B. III, Yarger, R. G. \& Epple, G. The major volatile constituents of the marmoset (Saguinus fuscicollis) scent mark. Tetrahedron Lett. 17, 983-986 (1976).

16 Smith, A. B. III, Belcher, A. M., Epple, G., Jurs, P. C. \& Lavine, B. Computerized pattern recognition: a new technique for the analysis of chemical communication. Science 228, 175-177 (1985).

17 Beauchamp, G. K. et al. Phytochemistry: Ibuprofen-like activity in extra-virgin olive oil. Nature 437, 45-46 (2005).

18 Smith, A. B. III, Sperry, J. B. \& Han, Q. Synthesis of ( - )-oleocanthal, a Natural NSAID found in extra virgin olive oil, the (-)-deacetoxy-oleuropein aglycone and related analogues. J. Org. Chem. 72, 6891-6900 (2007).

19 Cicerale, S., Breslin, P. A. S., Beauchamp, G. K. \& Keast, R. S. J. Sensory characterization of the irritant properties of oleocanthal, a natural anti-inflammatory agent in extra virgin olive oils. Chem. Senses 34, 333-339 (2009).

20 Martinez-Gonzalez, M. A. \& Bes-Rastrollo, M. Dietary patterns, Mediterranean diet, and cardiovascular disease. Curr. Opin. Lipidol. 25, 20-26 (2014).

21 Scotece, M. et al. New drugs from ancient natural foods: oleocanthal, the natural occurring spicy compound of olive oil: a brief history. Drug Disc. Today 20, 406-410 (2015).

22 Schreiber, S. L. Chemistry and biology of the immunophilins and their immunosuppressive ligands. Science 251, 283-287 (1991).

23 Hayward, C. M., Yohannes, D. \& Danishefsky, S. J. Total synthesis of rapamycin via a novel titanium-mediated aldol macrocyclization reaction. J. Am. Chem. Soc. 115, 9345-9346 (1993).

24 Jones, A. B., Villalobos, A., Linde, R. G. II \& Danishefsky, S. J. A formal synthesis of FK-506. Exploration of some alternatives to macrolactamization. J. Org. Chem. 55, 2786-2797 (1990).

25 Nicolaou, K. C., Chakraborty, T. K., Piscopio, A. D., Minowa, N. \& Bertinato, P. Total synthesis of rapamycin. J. Am. Chem. Soc. 115, 4419-4420 (1993).

26 Nerenberg, J. B., Hung, D. T., Somers, P. K. \& Schreiber, S. L. Total synthesis of the immunosuppressive agent (-)-discodermolide. J. Am. Chem. Soc. 115, 12621-12622 (1993).

27 Romo, D., Meyer, S. D., Johnson, D. D. \& Schreiber, S. L. Total synthesis of (-)-rapamycin using an Evans-Tishchenko fragment coupling. J. Am. Chem. Soc. 115, 7906-7907 (1993).

$28 \mathrm{Gu}$, R. L. \& Sih, C. J. Synthesis of the C 10-C 34 segment of the immunosuppressant FK506. Tetrahedron Lett. 31, 3287-3290 (1990).

29 Marshall, J. A. \& Johns, B. A. Total synthesis of (+)-discodermolide. J. Org. Chem. 63, 7885-7892 (1998).

30 Jones, T. K., Reamer, R. A., Desmond, R. \& Mills, S. G. Chemistry of tricarbonyl hemiketals and application of Evans technology to the total synthesis of the immunosuppressant (-)-FK-506. J. Am. Chem. Soc. 112, 2998-3017 (1990).

31 Smith, A. B. III, Condon, S. M. \& McCauley, J. A. Total synthesis of immunosuppressants: unified strategies exploiting dithiane couplings and $\sigma$-bond olefin constructions. Acc. Chem. Res. 31, 35-46 (1998).

32 Negishi, E., Van Horn, D. E. \& Yoshida, T. Controlled carbometalation. 20. Carbometalation reaction of alkynes with organoalane-zirconocene derivatives as a route to stereo-and regiodefined trisubstituted alkenes. J. Am. Chem. Soc. 107, 6639-6647 (1985).

33 Smith, A. B. III, Chen, K., Robinson, D. J., Laakso, L. M. \& Hale, K. J. Formal total synthesis of FK506. Concise construction of the $\mathrm{C}(10)-\mathrm{C}(34)$ segment via an effective coupling tactic. Tetrahedron Lett. 35, 4271-4274 (1994).

34 Smith, A. B. \& Hale, K. J. An enantioselective synthesis of the $C(10)$ to $C(23)$ backbone of the potent immunosuppressant FK506. Tetrahedron Lett. 30 1037-1040 (1989).

35 Smith, A. B., Hale, K. J., Laakso, L. M., Chen, K. \& Riéra, A. FK-506 synthetic studies. 3. An efficient asymmetric synthesis of the $C(24)-C(34)$ fragment of FK-506, FR-900520, and FR-900523. Tetrahedron Lett. 30, 6963-6966 (1989).

36 Smith, A. B. III et al. A unified total synthesis of the immunomodulators (-)-rapamycin and (-)-27-demethoxyrapamycin: assembly of the common C (1-20) perimeter and final elaboration. J. Am. Chem. Soc. 119, 962-973 (1997).

37 Fontes, E., Heiney, P. A., Ohba, M., Haseltine, J. N. \& Smith, A. B. III Molecular disorder in columnar-phase discotic liquid-crystal strands. Phys. Rev. A 37, 1329-1334 (1988).

38 Krätschmer, W., Lamb, L. D., Fostiropoulos, K. \& Huffman, D. R. Solid C60: a new form of carbon. Nature 347, 354-358 (1990).

39 Creegan, K. M. et al. Synthesis and characterization of C600, the first fullerene epoxide. J. Am. Chem. Soc. 114, 1103-1105 (1992).

40 Smith, A. B. III et al. Synthesis and characterization of the first C700 epoxides. Utilization of $3 \mathrm{He}$ NMR in analysis of fullerene derivatives. J. Org. Chem. 61, 1904-1905 (1996).

41 Chen, C. T. et al. Electronic states and phases of $\mathrm{K}_{\mathrm{x}} \mathrm{C}_{60}$ from photoemission and $\mathrm{X}$-ray absorption spectroscopy. Nature 352, 603-605 (1991).

42 Smith, A. B. III et al. Synthesis and ${ }^{3} \mathrm{He}$ NMR studies of $\mathrm{C} 60$ and $\mathrm{C} 70$ epoxide, cyclopropane, and annulene derivatives containing endohedral helium. J. Am. Chem. Soc. 116, 10831-10832 (1994).

43 Smith, A. B. III, Charnley, A. K. \& Hirschmann, R. Pyrrolinone-based peptidomimetics. 'Let the enzyme or receptor be the judge'. Acc. Chem. Res. 44, 180-193 (2011).

44 Hirschmann, R. F., Nicolaou, K. C., Angeles, A. R., Chen, J. S. \& Smith, A. B. III The $\beta$-D-glucose scaffold as a $\beta$-turn mimetic. Acc. Chem. Res. 42, 1511-1520 (2009).
45 Gellman, S. H. Foldamers: a manifesto. Acc. Chem. Res. 31, 173-180 (1998).

46 Smith, A. B. III et al. De novo design, synthesis, and X-ray crystal structures of pyrrolinone-based $\beta$-strand peptidomimetics. J. Am. Chem. Soc. 116, 9947-9962 (1994).

47 Smith, A. B. III et al. Design, synthesis, and crystal structure of a pyrrolinone-based peptidomimetic possessing the conformation of a $\beta$-strand: potential application to the design of novel inhibitors of proteolytic enzymes. J. Am. Chem. Soc. 114 10672-10674 (1992).

48 Merrifield, R. B. Solid phase peptide synthesis. I. The synthesis of a tetrapeptide. J. Am. Chem. Soc. 85, 2149-2154 (1963)

49 Snyder, L. R. Peer Reviewed: HPLC: past and present. Anal. Chem. 72 , 412-A-420-A (2000).

50 Abrahmsen, L. et al. Engineering subtilisin and its substrates for efficient ligation of peptide bonds in aqueous solution. Biochemistry 30, 4151-4159 (1991).

51 Lerner, R. A., Benkovic, S. J. \& Schultz, P. G. At the crossroads of chemistry and immunology: catalytic antibodies. Science 252, 659-667 (1991).

52 Hirschmann, R. et al. Peptide synthesis catalyzed by an antibody containing a binding site for variable amino acids. Science 265, 234-237 (1994).

53 Smith, A. B. III, Taylor, C. M., Benkovic, S. J. \& Hirschmann, R. Peptide bond formation via catalytic antibodies: synthesis of a novel phosphonate diester hapten. Tetrahedron Lett. 35, 6853-6856 (1994).

54 Petasis, N. A. \& Lu, S. P. Stereocontrolled synthesis of substituted tetrahydropyrans from 1,3-dioxan-4-ones. Tetrahedron Lett. 37, 141-144 (1996).

55 Minbiole, E. C. \& Minbiole, K. P. C. The Petasis-Ferrier rearrangement-developments and applications. J. Antibiot. 69, 213-219 (2016).

56 Smith, A. B. III, Minbiole, K. P., Verhoest, P. R. \& Schelhaas, M. Total synthesis of (+)-phorboxazole A exploiting the Petasis-Ferrier rearrangement. J. Am. Chem. Soc 123, 10942-10953 (2001).

57 Smith, A. B. III, Safonov, I. G. \& Corbett, R. M. Total syntheses of (+)-zampanolide and (+)-dactylolide exploiting a unified strategy. J. Am. Chem. Soc. 124 11102-11113 (2002).

58 Smith, A. B. III et al. Spongistatin synthetic studies. Evolution of a scalable synthesis for the EF fragment of (+)-spongistatin 1 exploiting a petasis-ferrier union/ rearrangement tactic. Org. Lett. 6, 3637-3640 (2004).

59 Smith, A. B. III, Mesaros, E. F. \& Meyer, E. A. Evolution of a total synthesis of (-)-kendomycin exploiting a Petasis-Ferrier rearrangement/ring-closing olefin metathesis strategy. J. Am. Chem. Soc. 128, 5292-5299 (2006).

60 Smith, A. B. III \& Simov, V. Total synthesis of the marine natural product (-)clavosolide A. A showcase for the Petasis-Ferrier union/rearrangement tactic. Org. Lett. 8, 3315-3318 (2006).

61 Smith, A. B. III, Basu, K. \& Bosanac, T. Total synthesis of (-)-okilactomycin. J. Am. Chem. Soc. 129, 14872-14874 (2007).

62 Seebach, D. Methods of reactivity umpolung. Angew. Chem., Int. Ed. 18 239-258 (1979).

63 Wittig, G., Davis, P. \& Koenig, G. Phenanthrensynthesen über intraionische Isomerisationen. Chem. Ber. 84, 627-632 (1951).

64 Wittig, G. From diyls to ylides to my idyll. Chemistry 1971-1980, 368-376 (1979).

65 Corey, E. J., Seebach, D. \& Freedman, R. Synthesis of $\alpha$-silyl ketones via 1, 3-dithianes. J. Am. Chem. Soc. 89, 434-436 (1967).

66 Smith, A. B. III \& Wuest, W. M. Evolution of multi-component anion relay chemistry (ARC): construction of architecturally complex natural and unnatural products. Chem. Commun. 45, 5883-5895 (2008)

67 Matsuda, I., Murata, S. \& Ishii, Y. A simple preparation of trimethylsilylacetonitrile and a novel ring-opening of epoxides with trimethylsilylacetonitrile anion. J. Chem. Soc. Perkin Trans. 1, 26-30 (1979).

68 Tietze, L. F., Geissler, H., Gewert, J. A. \& Jakobi, U. Tandem-bisalkylation of 2 trialkylsilyl-1, 3-dithiane: a new sequential transformation for the synthesis of $\mathrm{C} 2$ symmetrical enantiopure 1,5 -diols and $\beta, \beta^{\prime}$-dihydroxyketones as well as of enantiopure 1, 3, 5-triols. Synlett 7, 511-512 (1994).

69 Fischer, M. R., Kirschning, A., Michel, T. \& Schaumann, E. Syntheses of cyclopentanols by a silicon-induced cascade reaction. Angew. Chem. Int. Ed. 33, 217-218 (1994).

70 Smith, A. B. III \& Adams, C. M. Evolution of dithiane-based strategies for the construction of architecturally complex natural products. Acc. Chem. Res. 37, 365-377 (2004).

71 Chen, M. Z., Gutierrez, O. \& Smith, A. B. III. Through-bond/through-space anion relay chemistry exploiting vinylepoxides as bifunctional linchpins. Angew. Chem. Int. Ed. $\mathbf{5 3}$ 1279-1282 (2014).

72 Smith, A. B. III, Hoye, A. T., Martinez-Solorio, D., Kim, W.-S. \& Tong, R. Unification of anion relay chemistry (ARC) with the Takeda and Hiyama cross-coupling reactions: identification of an effective silicon-based transfer agent. J. Am. Chem. Soc. 134, 4533-4536 (2012).

73 Nguyen, M. H. \& Smith, A. B. III Recyclable Polystyrene-supported siloxane-transfer agent for palladium-catalyzed cross-coupling reactions. Org. Lett. 16, 2070-2073 (2014).

74 Smith, A. B. III, Kaufman, M. D., Beauchamp, T. J., LaMarche, M. J. \& Arimoto, H. Gram-scale synthesis of (+)-discodermolide. Org. Lett. 1, 1823-1826 (1999).

75 Smith, A. B. III, Qiu, Y., Jones, D. R \& Kobayashi, K. Total synthesis of (-)-discodermolide. J. Am. Chem. Soc. 117, 12011-12012 (1995).

76 Mickel, S. J. et al. Large-scale synthesis of the anti-cancer marine natural product (+)-discodermolide. Part 5: linkage of fragments $\mathrm{C}$ and $\mathrm{C}$ and finale. Org. Process Res. Dev. 8, 122-130 (2004)

77 Smith, A. B. III, Tomioka, T., Risatti, C. A., Sperry, J. B. \& Sfouggatakis, C. Gram-scale synthesis of (+)-spongistatin 1 . An improved, scalable synthesis of the F-ring subunit, fragment union, and final elaboration. Org. Lett. 10, 4359-4362 (2008). 
78 Smith, A. B. III, Razler, T. M., Meis, R. M \& Pettit, G. R. Synthesis and biological evaluation of phorboxazole congeners leading to the discovery and preparative-scale synthesis of (+)- chlorophorboxazole a possessing picomolar human solid tumor cell growth inhibatory activity. J. Org. Chem. 73, 1201-1208 (2008).

79 Chao, S. K. et al. Resistance to discodermolide, a microtubule-stabilizing agent and senescence inducer, is 4E-BP1-dependent. Proc. Natl Acad. Sci. USA 108, 391-396 (2011)

80 Klein, L. E., Freeze, B. S., Smith, A. B. III \& Horwitz, S. B. The microtubule stabilizing agent discodermolide is a potent inducer of accelerated cell senescence. Cell Cycle 4, 501-507 (2005).

81 Woodward, R. B. Recent advances in the chemistry of natural products. Science 153 , 487-493 (1966).

82 Lou, K. et al. Brain-penetrant, orally bioavailable microtubule-stabilizing small molecules are potential candidate therapeutics for alzheimer's disease and related tauopathies. J. Med. Chem. 57, 6116-6127 (2014).
83 Courter, J. R. et al. Structure-based design, synthesis and validation of CD4-mimetic small molecule inhibitors of HIV-1 entry: conversion of a viral entry agonist to an antagonist. Acc. Chem. Res. 47, 1228-1237 (2014).

84 Halford, B. Aiming for HIV's weak spot. Chem. Eng. News 92, 14-21 (2014).

85 Richard, J. et al. Small CD4 mimetics prevent HIV-1 uninfected bystander CD4+T cell killing mediated by antibody-dependent cell-mediated cytotoxicity. EBioMedicine 3, 122-134 (2016)

86 Richard, J. et al. CD4 mimetics sensitize HIV-1-infected cells to ADCC. Proc. Natl Acad. Sci. USA 112, E2687-E2694 (2015).

87 Melillo, B. et al. Small-molecule CD4-mimics: structure-based optimization of HIV-1 entry inhibition. ACS Med. Chem. Lett. (e-pub ahead of print 19 January 2016; doi: 10.1021/acsmedchemlett.5b00471).

88 Brown, S. P. \& Smith III, A. B. Peptide/protein stapling and unstapling: Introduction of s-tetrazine, photochemical release, and regeneration of the peptide/protein. J. Am. Chem. Soc. 137, 4034-4037 (2015). 